\title{
Adesão de crianças ao valor justiça: comparação entre respostas espontâneas e respostas a um questionário fechado
}

Adherence to the value of justice in children: a comparison between spontaneous answers and answers given to a structured questionnaire

\author{
Maria Suzana de Stefano Menin* \\ Universidade Estadual Paulista \\ Adriano Moro** \\ Fundação Carlos Chagas
}

Patrícia Unger Raphael Bataglia***

Universidade Estadual Paulista

Resumo O objetivo do presente estudo foi analisar a adesão ao valor justiça em crianças. Compararam-se as respostas dadas por crianças entre 9 e 12 anos a dois tipos de questionários: o primeiro, com alternativas construídas em níveis crescentes de descentração de perspectiva social, e o segundo, com as mesmas questões feitas de forma aberta. As questões foram apresentadas em formato de histórias que envolviam justiça distributiva, retributiva e comutativa. O questionário, com alternativas, foi aplicado em 111 crianças e o fechado, em outras 28. Em ambos os tipos de questionários, as crianças revelaram as mesmas tendências na adesão ao valor. No entanto, as respostas espontâneas mostraram-se mais punitivas e com uso mais forte de sanções expiatórias que as fechadas, no caso das histórias a respeito de justiça retributiva e comutativa.

PALAVRAS-chave: Justiça, Valor Moral, Escala de Avaliação.

Abstract The aim of this study was to assess adherence to the value justice in children. We compared the responses of children between 9 and 12 years, in two types of questionnaires: the first with alternatives, built in increasing levels of social perspective descentration, and the second with the same issues presented openly. The questions were presented in the form of stories involving distributive, commutative and retributive justice. The questionnaire with alternatives was applied in 111 children and the structured questionnaire in other 28. In both types of questionnaires children showed the same trends in adherence to the value, however, the spontaneous responses were more punitive and using stronger expiatory sanctions than in the closed one, in the case of stories about retributive and procedural justice.

KEYWORDS: Justice, Moral Value, Rating Scale. 


\section{Introdução}

A presente pesquisa deriva de um trabalho maior, realizado na Fundação Carlos Chagas (SP), por uma equipe de pesquisadores ${ }^{1}$ que tem como objetivo construir, validar (teórica e empiricamente) e aplicar, em amostras de crianças, adolescentes e professores de educação básica, uma escala de mensuração da presença e modo de adesão a valores morais. Essa escala dedica-se aos valores de respeito, solidariedade, convivência democrática e justiça e foi recentemente (2012) testada em cerca de 900 participantes. Para o presente texto, analisamos e discutimos os resultados obtidos, especificamente, nas questões sobre o valor de justiça, considerado por muitos, desde Aristóteles (2000), como o valor mais central e referência para todos os demais.

Para a definição do valor justiça, levamos em consideração os Parâmetros Curriculares Nacionais (BRASIL, 1998) ${ }^{2}$ e as conceituações, principalmente, de Piaget (1994) e Kohlberg (1992), e construímos uma matriz que contém, além de uma conceituação geral, definições de diferentes aspectos ou constituintes do valor e maneiras de aplicá-los em diferentes situações, chamados descritores. O Quadro 1 focaliza a matriz e descritores definidos para o valor justiça.

Quadro 1: Matriz e descritores do valor justiça

\begin{tabular}{|l|l|}
\hline \multicolumn{1}{|c|}{ Matriz } & \multicolumn{1}{|c|}{ Descritores } \\
\hline $\begin{array}{l}\text { A justiça é composta dos princípios de igual- } \\
\text { dade e equidade e articula-se com outros }\end{array}$ & - Afirmar e valorizar os princípios de justiça, \\
valores morais, como a dignidade, o respeito, & tanto de igualdade como de equidade, para \\
o diálogo. O princípio da igualdade é funda- & refletir, compreender, construir e aplicar re- \\
mental na justiça distributiva, para estabele- & grast normas ou leis. \\
cer critérios de atribuição de direitos e deve- & Identificar e repudiar situações (na família, \\
res entre todas as pessoas. O mesmo ocorre & na escola, nas mídias, na sociedade em ge- \\
na justiça retributiva, em relação à atribuição & ral e no meio ambiente) nas quais ocorram \\
de penalidades aos atos injustos, desrespeito- & desigualdades, discriminações, preconceitos, \\
sos e relativos às infrações. & $\begin{array}{l}\text { incluídos ou não em situações de diversidade } \\
\text { social. } \\
- \text { Identificar e repudiar situações em que haja } \\
\text { favorecimento de uns em função do prejuízo } \\
\text { de outros, resultantes de desrespeito a direi- } \\
\text { tos ou de tratamento desigual. } \\
- \text { Na aplicação de penalidades a ações des- } \\
\text { respeitosas, ou mesmo infrações às regras, } \\
\text { normas e leis consideradas justas, priorizar } \\
\text { sanções por reciprocidade, que busquem res- } \\
\text { taurar as relações sociais e não sanções expia- } \\
\text { tórias, que só almejam o castigo. } \\
- \text { Compreender e responsabilizar-se por deci- } \\
\text { sões resultantes de contratos firmados demo- } \\
\text { craticamente pelas partes. }\end{array}$ \\
\hline
\end{tabular}

Fonte: Dados da pesquisa

As histórias montadas para esta pesquisa basearam-se em três acepções de justiça: retributiva, distributiva e comutativa. Podemos pensar no conceito de justiça 
ligado à sanção. Uma sanção pode ser injusta, quando pune um inocente, recompensa um culpado ou, ainda, quando a dose da consequência atribuída ao ato não parece correta. Essa acepção se relaciona à justiça retributiva. Por outro lado, uma repartição é injusta, quando favorece uns à custa de outros. Essa é a acepção ligada à justiça distributiva (PIAGET, 1994). A justiça comutativa centra-se num acordo voluntário, no contrato e no intercâmbio entre iguais.

Para cada acepção de justiça, podemos pensar em várias alternativas de respostas para as histórias. A fim de estabelecer essas alternativas e suas categorias de análise, adotamos os estudos de Kohlberg (1992), o qual propôs que o desenvolvimento do juízo moral se dá como uma estrutura de justiça que vai progressivamente se tornando mais e mais abrangente, diferenciada e equilibrada do que a estrutura inicial. Os estádios de desenvolvimento moral se sucedem de acordo com uma sequência invariável. Kohlberg (1992) define três níveis de desenvolvimento moral: pré-convencional, convencional e pós-convencional. Cada nível é composto por dois estádios.

De acordo com Kohlberg (1992), além de os níveis de raciocínio moral dependerem de um desenvolvimento cognitivo (relação necessária, mas não suficiente), dependem, igualmente, de uma evolução na perspectiva social ou percepção social, ou, ainda, habilidade de assunção de papéis (roletaking). Há estádios de desenvolvimento de perspectiva social que seriam mais gerais que os de desenvolvimento moral, pois não tratam especificamente da justiça, nem de escolher entre o que é correto ou incorreto. Kohlberg (1992) correlaciona os três níveis de juízo moral a três níveis de perspectivas sociais, que nomeia de perspectiva individual concreta (paralela ao nível pré-convencional); perspectiva de membro da sociedade (nível convencional) e perspectiva para além da sociedade (pós-convencional).

No pré-convencional, o indivíduo pensa em seu próprio interesse e no de outros indivíduos isolados que lhe afetem. No nível convencional, o que une o indivíduo à perspectiva social é o ponto de vista compartilhado com o grupo. $\mathrm{O}$ indivíduo subordina os pontos de vista de uma pessoa aos do grupo ou às relações compartilhadas. No nível pós-convencional, leva-se em conta, sobretudo, o ponto de vista possível de qualquer indivíduo moral racional. Leis e deveres devem ser tais que qualquer pessoa racional possa comprometer-se com eles, em qualquer sociedade. Nesse caso, o indivíduo não se compromete com nenhum grupo ou sociedade, mas com um ponto de vista moral, mais que tudo. O correto refere-se aos princípios universalizáveis de moral para toda e qualquer pessoa racional. É sinônimo da Dignidade (KOHLBERG, 1992).

Seguindo essas indicações de Kohlberg para as perspectivas sociais, buscamos construir as alternativas pró-valor e contravalor em níveis crescentes de descentração social. Assim, destacamos, nos níveis, respectivamente, uma perspectiva individualista ou egocentrada (nível 1), outra centrada nas relações grupais, familiares e em normas sociais mais convencionais (nível 2), e, finalmente, outra perspectiva, mais descentrada socialmente, baseada em contratos estabelecidos democraticamente por meio de procedimentos justos e em princípios considerados “universalizáveis" (nível 3). $\mathrm{Na}$ escala, em função dessas perspectivas sociais, correspondentes a níveis, colocamos cinco alternativas; três em que o valor focado é afirmado, sendo uma em cada um dos 
níveis de perspectiva social (nível 1, P1, nível 2, P2, e nível 3, P3) e duas alternativas que afirmam o contravalor correspondente, sendo uma delas no nível 1 (C1) e outra no nível 2 (C2). Entendemos como contravalor afirmativas que se opõem ao valor de justiça de formas variadas, seja pelo abuso da autoridade, seja pela indiferença, omissão ou arbitrariedade.

Os objetivos propostos, nesta pesquisa, foram:

- identificar entre as formas de justiça - retributiva, distributiva e comutativa -, qual delas provocou maiores diferenças entre crianças em relação à adesão, ou não, a pró-valores (alternativas $\mathrm{P}$ ) ou contravalores (alternativas $\mathrm{C}$ ) e o alcance, ou não, dos níveis mais elevados de justiça (níveis P3);

- analisar as respostas das crianças aos itens de justiça distributiva, retributiva e comutativa, comparando as respostas abertas àquelas dadas, às mesmas questões no questionário fechado, quando foram oferecidas alternativas em pró e contra valores de justiça e em níveis crescentes de perspectiva social.

Como hipóteses a serem verificadas, propusemos:

1. há uma progressão na escolha das respostas em relação aos níveis, ou seja, o nível P3 é mais escolhido do que o P2 e este mais do que o P1. O mesmo se aplica aos contravalores, isto é, o nível C2 é mais escolhido do que o $\mathrm{C} 1$.

2. As respostas às questões abertas expressam os diferentes níveis na mesma sequência que nas questões fechadas.

3. Há diferenças entre as três formas de justiça distributiva, retributiva e comutativa no alcance dos níveis $\mathrm{P} 3$, sendo provável que perspectivas sociais baseadas em instituições ou autoridades influam mais nas duas últimas formas de justiça, atrasando o alcance de respostas em P3.

\section{Método}

Para o presente estudo, consideraremos as respostas dadas por 111 crianças às questões fechadas e por 28 crianças aos mesmos itens, em questões abertas. As questões referentes à justiça foram num total de nove itens distribuídos em três cadernos, da seguinte forma: nos cadernos 1 e 2 ( $\mathrm{C} 1$ e $\mathrm{C} 2)$, selecionamos um item de cada tipo de justiça (retributiva, distributiva e comutativa) e, no caderno 3 (C3), selecionamos dois itens de justiça distributiva e um de justiça retributiva.

A construção das questões seguiu sempre um mesmo padrão. Apresentamse pequenas histórias (cerca de quatro linhas de enunciado) na forma de situações-problema com cenas que representam o cotidiano de crianças e jovens. As histórias terminam com uma frase a completar ou uma questão sobre o que se deveria fazer, ou o que seria melhor fazer na situação apresentada. $\mathrm{O}$ respondente deve ler a questão e escolher a alternativa que, segundo ele, indica a conduta mais correta (moralmente falando) para a situação descrita. No questionário fechado, são dadas como alternativas sempre cinco possibilidades, sendo três delas favoráveis ao valor mais focalizado na questão (alternativas $\mathrm{P}$, ou pró-valor) e duas contrárias a ele (alternativas $\mathrm{C}$ ou contravalor); ou 
seja, baseiam-se num contravalor. As histórias contêm alternativas pró-justiça, como igualdade ou equidade (justiça distributiva), sanções por reciprocidade (justiça retributiva) ou contratos realizados de forma dialógica e democrática (justiça comutativa), ou contravalores, tais como desigualdades, preconceitos, favoritismo, sanções expiatórias, arbitrárias ou injustas, procedimentos ou processos de julgamento autoritários e incorretos etc. Além das posições pró ou contra os valores, as alternativas foram elaboradas numa perspectiva construtivista, em função da perspectiva social presente nos níveis sociomorais de Kohlberg (1992) - pré-convencional, convencional, pós-convencional.

No questionário aberto, utilizamos as mesmas histórias usadas nas questões do questionário fechado mas, em vez de apresentarmos as cinco alternativas, isto é, deixamos a história em aberto e o respondente é que deve dizer o que se deve fazer, na situação.

A qualidade técnica dos questionários aplicados foi verificada por meio dos procedimentos estatísticos indicados pela Teoria Clássica do Teste. Para tanto, empregamos o processamento ITEMAN, que se fundamenta em parâmetros descritivos, os quais auxiliam na interpretação da distribuição das respostas em cada alternativa, em cada item, analisando, portanto, o caderno de questões como um todo. As características psicométricas dos itens de um questionário correspondem aos seguintes parâmetros: índice de dificuldade (proporção de participantes que responderam ao item corretamente $)^{3}$ e índice de discriminação, que avalia a capacidade do item de diferenciar os participantes de maior habilidade ou desempenho ( $27 \%$ dos respondentes com pontuações mais altas) daqueles de menor habilidade ( $27 \%$ dos respondentes com pontuações mais baixas), correspondendo à diferença entre a proporção de acertos entre estes dois grupos ${ }^{4}$ (VIANNA, 1982).

\section{Resultados}

Apresentaremos, a seguir, dados gerais a respeito dos índices de dificuldade e de discriminação segundo o que foi retornado pelo software ITEMAN, para, depois, analisarmos em separado as respostas dadas aos itens de cada tipo de justiça.

\section{Resultados da análise de itens pela Teoria Clássica do Teste}

Com base nas análises do ITEMAM, construímos as Tabelas 1 e 2, que ilustram, respectivamente, os índices de dificuldade e de discriminação dos itens de justiça da escala. Podemos verificar, na Tabela 1, as classificações dos itens objetivos segundo o índice de dificuldade. Os dados indicam que, para o grupo de crianças avaliadas, quatro itens foram considerados difíceis (entre 16\% e $40 \%$ de acertos), dois como de média dificuldade (entre $41 \%$ e $60 \%$ de acertos), dois como fáceis (entre $61 \%$ e $85 \%$ de acertos) e um como muito fácil (mais de $86 \%$ de acertos). Nenhuma questão foi tomada como muito difícil (tendo menos de $15 \%$ de acertos). Esses dados já demonstram que as questões de justiça distributiva foram as mais fáceis para as crianças desta pesquisa, quando comparadas com as questões de justiça retributiva e comutativa. 
Tabela 1: Classificação dos itens objetivos segundo o índice de facilidade

\begin{tabular}{c|c|c}
\hline Índice de Facilidade & Classificação & Questões \\
\hline$\geq 0,86$ & Muito fácil & C3_01 \\
0,61 a 0,85 & Fácil & C1_05, C2_09 \\
0,41 a 0,60 & Médio & C2_05, C3_05 \\
0,16 a 0,40 & Difícil & C1_01, C1_09, C2_01, \\
$\leq 0,15$ & & C3_09 \\
\hline
\end{tabular}

Fonte: Dados da pesquisa

A Tabela 2 exibe os percentuais de respostas em cada nível de contra e próvalores e seus respectivos índices de dificuldade e discriminação. Tendo-se em vista que os valores recomendados como referência para itens que conseguem atingir boa discriminação estão entre 0,30 e 0,39 pontos, conclui-se que apresentaram boa confiabilidade. Passamos, portanto, a mostrar os resultados por tipo de justiça.

Tabela 2: Percentuais de respostas nas alternativas contra e pró-valores e índices de dificuldade e discriminação

\begin{tabular}{|c|c|c|c|c|c|c|c|c|}
\hline Justiça & Itens & $\mathrm{C} 1$ & $\mathrm{C} 2$ & P1 & P2 & P3 & $\begin{array}{c}\text { Índice de } \\
\text { Dificuldade }\end{array}$ & $\begin{array}{c}\text { Índice de } \\
\text { Discriminação }\end{array}$ \\
\hline \multirow[t]{2}{*}{ Retributiva } & \multirow[t]{2}{*}{ C1_01 } & 05 & 60 & 11 & 02 & 33 & \multirow[t]{2}{*}{0,30} & \multirow[t]{2}{*}{0,34} \\
\hline & & $5 \%$ & $54 \%$ & $10 \%$ & $2 \%$ & $30 \%$ & & \\
\hline \multirow[t]{2}{*}{ Retributiva } & \multirow[t]{2}{*}{ C2_01 } & 13 & 19 & 40 & 11 & 26 & \multirow[t]{2}{*}{0,24} & \multirow[t]{2}{*}{0,30} \\
\hline & & $12 \%$ & $17 \%$ & $37 \%$ & $10 \%$ & $24 \%$ & & \\
\hline \multirow[t]{2}{*}{ Retributiva } & \multirow[t]{2}{*}{ C3_09 } & 12 & 32 & 03 & 24 & 35 & \multirow[t]{2}{*}{0,33} & \multirow[t]{2}{*}{0,46} \\
\hline & & $11 \%$ & $30 \%$ & $3 \%$ & $23 \%$ & $33 \%$ & & \\
\hline \multirow[t]{2}{*}{ Comutativa } & \multirow[t]{2}{*}{ C1_09 } & 02 & 01 & 35 & 30 & 43 & \multirow[t]{2}{*}{0,39} & \multirow[t]{2}{*}{0,41} \\
\hline & & $2 \%$ & $1 \%$ & $32 \%$ & $27 \%$ & $39 \%$ & & \\
\hline \multirow[t]{2}{*}{ Comutativa } & \multirow[t]{2}{*}{ C2_05 } & 04 & 18 & 02 & 35 & 50 & \multirow[t]{2}{*}{0,46} & \multirow[t]{2}{*}{0,41} \\
\hline & & $4 \%$ & $17 \%$ & $2 \%$ & $32 \%$ & $46 \%$ & & \\
\hline \multirow[t]{2}{*}{ Distributiva } & \multirow[t]{2}{*}{ C3_05 } & 12 & 08 & 20 & 13 & 53 & \multirow[t]{2}{*}{0,50} & \multirow[t]{2}{*}{0,48} \\
\hline & & $11 \%$ & $8 \%$ & $19 \%$ & $12 \%$ & $50 \%$ & & \\
\hline \multirow[t]{2}{*}{ Distributiva } & \multirow[t]{2}{*}{ C1_05 } & 03 & 10 & 02 & 10 & 86 & \multirow[t]{2}{*}{0,77} & \multirow[t]{2}{*}{0,30} \\
\hline & & $3 \%$ & $9 \%$ & $2 \%$ & $9 \%$ & $77 \%$ & & \\
\hline \multirow[t]{2}{*}{ Distributiva } & \multirow[t]{2}{*}{ C2_09 } & 03 & 07 & 13 & 06 & 80 & \multirow[t]{2}{*}{0,73} & \multirow[t]{2}{*}{0,37} \\
\hline & & $3 \%$ & $6 \%$ & $12 \%$ & $6 \%$ & $73 \%$ & & \\
\hline \multirow[t]{2}{*}{ Distributiva } & \multirow[t]{2}{*}{ C3_01 } & 00 & 00 & 08 & 06 & 91 & \multirow[t]{2}{*}{0,86} & 0,12 \\
\hline & & $0 \%$ & $0 \%$ & $8 \%$ & $6 \%$ & $87 \%$ & & \\
\hline
\end{tabular}

Fonte: Dados da pesquisa. 


\section{As respostas sobre Justiça Retributiva}

As histórias sobre Justiça Retributiva estiveram presentes nos três cadernos, isto é, um item em cada um deles. Tais histórias dizem respeito às situações que envolvem as consequências atribuídas às infrações, como penas ou castigos aos faltosos. No item 01 do Caderno 1, por exemplo, um aluno insiste em usar boné na escola, ainda que haja explícita uma regra proibindo tal comportamento. No item 01 do Caderno 2, os alunos, por diversão, picham as paredes da escola e, nesse caso, pergunta-se qual a atitude possível da escola. No item 09 do Caderno 3, uma mãe enfrenta problemas com seus filhos, pois, apesar de combinado muitas vezes com os mesmos, sempre que ela chega em casa, encontra tudo em desordem, de forma que se pergunta o que ela deveria fazer.

As alternativas propostas para as três histórias contaram com três níveis em pró-valor: P1 - perspectiva egocentrada; por exemplo: a diretora da escola sugere rever as regras quanto à utilização de bonés simplesmente para evitar problemas na escola e não entrar em conflito com o aluno; P2 - perspectiva no grupo, na instituição, ou regras; por exemplo: a escola propõe uma conversa com os alunos que picharam os muros, sugerindo que os alunos contratem um pintor e paguem pelo prejuízo; P3 - há o reconhecimento de interesses mútuos e a necessidade de acordos para que se estabeleça o respeito e se assegurem os direitos e deveres de todos os envolvidos num contrato; no caso de uma família, a mãe combina juntamente com seus filhos o que cada um deveria fazer, assim como as possíveis sanções, se não cumprissem o combinado.

As duas alternativas de contravalor refletem antivalores, como arbitrariedade e autoritarismo. Na história da diretora, esta aplica três dias de suspensão a Marcos por usar boné na escola (perspectiva egocêntrica). Em outra história, visando a punir os transgressores, mas respeitando as convenções, a diretora atribui aos pais a responsabilidade pelos filhos terem pichado o muro da escola e exige deles uma indenização.

A Tabela 2 evidencia, quanto aos dados referentes à justiça retributiva, que o percentual de respostas nas alternativas apresentou variações para os três itens avaliados. Na questão 01 do Caderno 1, o percentual mais elevado foi para o contravalor C2, com $54 \%$ das respostas. Na questão 09 do Caderno 3, ainda que o maior percentual tenha sido o P3 (33\%), o C2 ficou muito próximo, ou seja, 30\% das respostas. Somente na questão 01 do Caderno 2 o contravalor $\mathrm{C} 2$ foi baixo (17\%), quando o que sobressaiu foi o pró-valor $\mathrm{P} 1$ com $37 \%$ das respostas.

Verificamos, também, que os três itens de justiça retributiva foram difíceis, quer dizer, não são itens óbvios, permitindo variação pelos níveis de respostas distribuídas nas alternativas.

É importante acrescentar que o item 09 do Caderno 3 foi classificado como sendo muito discriminativo. Ou seja, foi capaz de separar nitidamente os grupos superiores e inferiores em relação ao P3. Assim, 33\% das crianças optaram pela alternativa P3. Por outro lado, $30 \%$ escolheram o contravalor C2; são respostas que se opõem e identificam os grupos no ITEMAN. As alternativas, nesse item, sugeriram desde deixar os filhos de castigo (C1), deixá-los de castigo para reconhecerem a importância das 
regras (C2), fazer bagunça no quarto deles também (P1), não fazer algo que pedissem, para sentirem a importância de cumprirem com os combinados (P2), até combinar com eles o que cada um deveria fazer e o que deveria acontecer caso não cumprissem com o combinado (P3).

Quando analisamos os itens abertos, sem alternativas dirigidas e, consequentemente, que permitiram que as respostas das crianças fossem dadas de modo espontâneo, verificamos que o nível de respostas foi muito voltado ao contravalor C2. O item 09 do Caderno 3 foi respondido por 27 crianças, sendo a maioria das respostas classificada como C2. O termo mais utilizado nas respostas foi "castigo". As crianças, quase na totalidade, optaram por sanções.

Podemos dizer que, nos itens fechados, por apresentarmos outras alternativas, como as de $\mathrm{P} 2$ e P3, o percentual nos pró-valores foi elevado. No entanto, quando livres para determinarem o que a mãe deveria fazer com seus filhos, o que ocorreu nos faz concordar com Piaget (1994), para quem existe uma tendência das crianças menores em serem bastante severas, quando escolhem as sanções para punir outras crianças: optaram, na sua maioria, por sanções expiatórias.

\section{As respostas sobre Justiça Distributiva}

No conjunto de questões sobre justiça distributiva, foram colocadas quatro pequenas histórias. Uma no Caderno 1 (item 05), outra no Caderno 2 ( item 09), e duas no Caderno 3 (itens 01 e 05), como nos mostra a Tabela 2. Em todas essas questões, podemos notar que foram alcançados os índices mais altos nas respostas de alternativa P3. As histórias de justiça distributiva, com situações semelhantes, questionam se é um dever ou não dar igual tratamento (ou atribuir os mesmos direitos) a pessoas diferentes por classe social, necessidades especiais ou por comportamento em sala de aula.

Na primeira questão (item 05, Caderno 1), um guarda se vê frente a três crianças de rua que querem entrar numa exposição de livros infantis; na segunda questão (item 09, Caderno 2), um diretor de clube deve escolher algumas crianças para aparecerem no site e, entre elas, há uma menina gorda que deseja muito participar; na terceira história (item 01, Caderno 3), questiona-se se um cadeirante deve ir ou não a um programa de TV a que uma escola foi convidada, considerando-se as dificuldades de locomoção e acesso; finalmente, na última história (item 05, Caderno 3), perguntase se uma professora dá mais ou menos atenção ou trata da mesma forma os alunos de sua classe, quando há os do "fundão", os quais conversam muito e atrapalham a aula.

Em todas as histórias, as alternativas pró-valor ofereceram três níveis em pró-valor e dois em contravalor, como nas histórias de justiça retributiva.

Podemos perceber, na Tabela 2, que as questões de justiça distributiva foram as que obtiveram os índices $\mathrm{P} 3$ maiores em comparação a todas as demais questões de justiça. Foram também os itens menos difíceis (níveis mais altos que 0,60 significam itens muito fáceis), isto é, nos quais os níveis de P3 foram facilmente reconhecidos como a resposta mais correta ou adequada de ser escolhida. Há, entre eles, igualmente, 
itens que foram muito pouco discriminativos, como a questão sobre o cadeirante, com índice de discriminação 0,12, o mais baixo entre todas as histórias de justiça, ou seja, não provocou diferenças entre as crianças que tiveram altas ou baixas respostas em P3.

Finalmente, a questão 09, do Caderno 3, merece atenção especial, por nela se ter obtido um índice percentual de P3 menor que nas demais - 50\%; o que resultou num item médio de dificuldade $(0,50)$ e muito bom quanto à capacidade de ser discriminativo $(0,48)$. Ao analisarmos esse item, constatamos que a questão que fizemos às crianças induziu uma resposta mais fatual que moral. Quer dizer, no final da história, se perguntou: "Quando surgem dúvidas, a professora...", e se ofereceram alternativas de ação da professora, nas quais ela dá ou não mais atenção aos alunos por diferentes razões, desde dar mais atenção aos da frente, porque os do fundo a atrapalham $(\mathrm{C} 1)$, ou porque os da frente seguem a regra de não atrapalhar a aula (C2), ou tratar todos iguais, para evitar problemas com os alunos (P1), porque essa é a regra da escola (P2), e porque todos merecem igual atenção (P3).

Parte das crianças respondeu guiando-se por ocorrências da realidade - o que as professoras costumam fazer, e não o que deveriam fazer - culminando numa distribuição de respostas entre as várias alternativas, como se pode observar na Tabela 2, nas porcentagens em $\mathrm{P} 1, \mathrm{P} 2$ e até mesmo em $\mathrm{C} 1$ e C2, tão pouco marcadas nas demais histórias de justiça. Isto é, nada obrigou, nessa questão, que os participantes se posicionassem apenas moralmente.

No questionário aberto para essa mesma questão, as respostas se dividiram entre os que acharam que a professora não poderia ou não deveria dar um tratamento igualitário (11 crianças, em 28) e os que acharam que ela deveria fazer isso; ou seja, a resposta afirmativa apelou para o dever moral (17 em 28). A resposta negativa sobre o tratamento igualitário foi mais fatual que moral. Assim, por misturar o que ocorre na realidade com o que deveria acontecer, tivemos, nessa história de justiça distributiva, e apenas nela, entre as quatro do questionário, um P3 menor que 70\% das alternativas fechadas e com tendência diferente nas respostas abertas.

\section{As respostas sobre justiça comutativa}

Foram usadas duas histórias sobre justiça comutativa. A questão do Caderno 1 (item 9) conta a história de um pai que combinou com seus filhos que lhes daria um computador no Natal; entretanto, decidiu usar o dinheiro para ir com os amigos a uma pescaria. As alternativas propostas são no sentido do dever do pai em cumprir sua promessa, por motivos que variam da perspectiva hedonista (deveria cumprir a promessa que fez para os filhos, porque vai deixá-los tristes - P1), legalista (deveria cumprir a promessa que fez para os filhos, pois é assim que a sociedade espera que ele faça como pai - P2) e contratual (deveria cumprir a promessa que fez para os filhos, porque eles haviam combinado dessa forma - P3), exibindo, também, o contravalor da autoridade, seja por motivo individualista (pode modificar a regra, porque assim ele terá a oportunidade de ir para um passeio que ele gosta muito de fazer - C1), seja em função da autoridade convencional (pode modificar a regra, porque ele é o pai-C2). 
De acordo com os índices explicitados nas Tabelas 1 e 2, essa história se mostrou difícil e com um índice de discriminação de escolha da alternativa P3 muito bom. As análises dos índices das respostas mostram, ainda, que as escolhas das crianças, nesse item, foram em direção ao pró-valor. $\mathrm{O}$ contravalor teve uma rejeição bastante intensa, tendo sido escolhido apenas por 3\% das crianças, tanto no nível 1 quanto no nível 2.

As análises das respostas abertas confirmaram essa tendência em quase todas as respostas. A única exceção foi a de uma criança, que disse: "compra um computador para eles no Natal do ano que vem", concordando, portanto com a ideia da soberania da escolha paterna. Nas respostas abertas, houve um predomínio quase absoluto do nível 3, de que o combinado entre as partes deveria ser cumprido.

A segunda história diz respeito a uma situação familiar em que duas irmãs, brincando com bola em casa, quebram um vaso e a mãe, ao chegar, exige que uma delas, a mais bagunceira, limpe a sujeira. As alternativas pró-valor da justiça comutativa democrática variam da argumentação mais hedonista (mal, pois, Miriam vai brigar com a mãe - P1), convencional (mal, pois como mãe, ela deveria saber o que aconteceu - P2) até a postura mais democrática (mal, porque não viu o que aconteceu e as meninas deveriam ser ouvidas - P3). O contravalor autoridade também traz um argumento egocêntrico (bem, porque Miriam é mais bagunceira e sempre perturba sua mãe - C1) e outro legalista (bem, porque os pais sabem sempre como agir - C2).

Essa história obteve um índice de dificuldade mediano e um índice de discriminação do argumento P3 muito bom. Aqui, diferentemente da história anteriormente examinada, verificamos que houve uma rejeição, não ao contra argumento, mas ao argumento do nível 1 (egocêntrico), tanto no argumento pró-valor, quanto no contravalor. Apenas $6 \%$ das crianças escolheram os argumentos P1 e C1.

Nas respostas abertas, a maioria das argumentações foi em direção à autoridade materna. Já as respostas de contravalor mostraram a valorização do castigo imposto pela mãe para "a menina aprender", isto é, o valor da autoridade e da necessidade de punição como forma de se evitarem novas ocorrências. Nas respostas abertas, apareceram muito mais argumentos ligados à justiça retributiva expiatória do que à justiça comutativa. As alternativas propostas não ofereciam possibilidades de sanção, mas a valorização da autoridade ou diálogo. Nessa situação, a história se revelou com alto índice de discriminação para as respostas convencionais e pós-convencionais.

\section{Considerações finais}

Em síntese, expressamos nossa convicção em prol da primeira hipótese proposta na pesquisa, pois houve, nas três formas de justiça, uma progressão na escolha das respostas em relação aos níveis; quer dizer, o nível P3 foi mais escolhido do que $\mathrm{P} 2$ e este mais do que $\mathrm{P} 1$. O mesmo se aplicou aos contravalores, isto é, o nível C2 foi mais escolhido do que $\mathrm{C} 1$. Esse resultado era o esperado, em função dos resultados encontrados em vários estudos. Rest et al. (1999) afirmam que o desenvolvimento moral é um movimento ascendente, em termos de mudanças graduais no uso e preferência 
por pensamentos morais mais desenvolvidos. Kohlberg (1984; 1976), Rest (1973) e Lind (1989) enfatizam, com base em seus estudos, a ordem hierárquica de preferências das orientações morais. Enfim, os achados, neste estudo, confirmam uma preferência de acordo com a hierarquia dos níveis propostos por Kohlberg (1984). Vale ressaltar que tais níveis não constituem estádios duros propriamente ditos, mas orientações morais, tendências afetivas que se sucedem na psicogênese.

De certa forma, a segunda hipótese também se confirmou; ou seja, as respostas às questões abertas expressaram os diferentes níveis, na mesma sequência na qual aconteceram nas escolhas nas questões fechadas, embora tenhamos observado que, nas formas de justiça retributiva e comutativa, as crianças foram mais rigorosas no uso de sanções expiatórias nas respostas abertas que nas fechadas.

De certa maneira, esses resultados indicam, por um lado, que as alternativas propostas correspondem às respostas as quais as crianças dariam, espontaneamente, e, de outro, que as alternativas podem induzir a níveis mais altos de respostas que aqueles em que os respondentes se encontram.

Quanto à terceira hipótese, houve diferenças entre as três formas de justiça consideradas, no alcance dos níveis P3. A justiça distributiva alcançou o nível P3 de modo mais fácil que as demais concepções de justiça. $\mathrm{O}$ que esse desempenho nas histórias de justiça distributiva pode nos mostrar é que o valor de igualdade entre os respondentes foi apoiado muito fortemente numa perspectiva moral, tornando-se uma escolha quase óbvia entre as crianças. Esse resultado era esperado pela teoria piagetiana, segundo a qual crianças, nessa faixa etária, já se posicionariam fortemente pela igualdade nos tratamentos, principalmente a igualdade absoluta (PIAGET, 1994). La Taille (2006) também comenta sobre a precocidade da adesão à igualdade por crianças pequenas como um dos primeiros sentimentos morais a se firmar. Seria de se esperar, também, que, quando contrapostas à autoridade, as escolhas pela justiça pudessem diminuir, o que não aconteceu nessas histórias.

\section{Referências}

ARISTÓTELES. Ética a Nicômaco. Rio de Janeiro: Nova Cultural, 2000 (Coleção "Os Pensadores").

BRASIL. Parâmetros Curriculares Nacionais: Apresentação dos Temas Transversais, Ética. Brasília: Ministério de Educação e do Desporto - MEC/Secretaria de Educação Fundamental, 1998.

KOHLBERG, L. Moral stages and moralization: The cognitive- developmental approach. In: LICKONA, T. (Ed.) Moral development and behavior: Theory, research and social issues. New York: Holt, Rinehart \& Winston, 1976, p. 31-53.

Essays on moral development, Vol. II, The psychology of moral development. San Francisco: CA: Harper \& Row, 1984. 1992.

Psicologia del desarrollo moral. Bilbau: Biblioteca de Psicologia, Desclée de Brouwer,

LA TAILLE, Y. Moral e Ética. Dimensões intelectuais e Afetivas. Porto Alegre: Artmed, 2006. 
LIND, G. Measuring moral judgment: A review of 'The Measurement of Moral Judgment' by Anne Colby, Lawrence Kohlberg et al. Human Development, v. 32, p. 388-397, 1989.

PIAGET, J. O Juízo moral na criança. São Paulo: Summus, 1994 (Obra original publicada em 1932).

REST, J. et al. Postconventional moral thinking: a neo-kohlbergian approach. Mahwah: Lawrence Erlbaum Associates, 1999.

VIANNA, H. M. Testes em Educação. São Paulo: Ibrasa, 1982.

\section{Notas}

\footnotetext{
${ }^{1}$ Marialva Tavares (Fundação Carlos Chagas - coordenação) Maria Suzana S. Menin (UNESP - coordenação); Adriano Moro (Fundação Carlos Chagas); Denise D’Aurea Tardeli (Univ. Metodista); Luciene P. Tognetta (UNIFRAN); Patricia U. Bataglia (UNESP); Raul Aragão Martins (UNESP); Telma P. Vinha (UNICAMP).Estatísticos: Dalton E. Andrade (UFSC); Miriam Bizzocchi (FCC); Raquel C. Valle (FCC).

${ }^{2}$ Os Parâmetros Curriculares Nacionais (PCN, 1998) são referenciais para a educação brasileira que definem e explicam vários temas para a Educação Básica. Um dos conjuntos de temas são os chamados temas transversais, que incluem a Ética e que destacam os valores de respeito, solidariedade, justiça e convivência democrática como os mais importantes de serem trabalhados em vários espaços da escola, quer dentro de disciplinas pedagógicas, quer como espaços relacionais.

${ }^{3}$ A alternativa considerada correta para o processamento é a classificada como P3 (Pró-valor de nível 3).

${ }^{4}$ Para o cálculo dos grupos (superior e inferior), a proporção de acerto centra-se na alternativa P3 (pró-valor de nível 3) de cada item.
}

* Professora Doutora da Universidade Estadual Paulista Júlio de Mesquita Filho, Presidente Prudente, São Paulo, Brasil

** Doutorando da Universidade Estadual de Campinas, Campinas, São Paulo, Brasil.

**** Professora Doutora da Universidade Estadual Paulista Júlio de Mesquita Filho, Marília, São Paulo, Brasil.

\section{Correspondência}

Maria Suzana de Stefano Menin - Universidade Estadual Paulista Júlio de Mesquita Filho, Faculdade de Ciências e Tecnologia de Presidente Prudente, Departamento de Educação. Rua Roberto Simonsen, 305, Centro Educacional. CEP: 19060-900 - Presidente Prudente, São Paulo, Brasil.

E-mail: menin@fct.unesp.br - amoro@fcc.org.br - patriciaurbataglia@gmail.com

Recebido em 22 de maio de 2013

Aprovado em 04 de abril de 2014 